\section{DRUG DEVELOPMENT}

\section{The invisible front line}

\section{The paid participants in phase I clinical trials need more protection, finds Meredith Wadman.}

$\mathrm{A}$ n essential step in bringing a new drug to market is the first testing of the product in humans. Phase I clinical trials are safety studies, typically conducted in fewer than 100 healthy subjects. The new drug's concentration and duration in the blood are tracked at various doses, and any toxic effects are monitored. Volunteers are paid for their participation.

Since the US Food and Drug Administration barred prisoners - until then the main source of paid subjects - from participating in clinical trials in 1980, a new class of 'professional human guinea pig' has stepped forward. Roberto Abadie, a visiting ethnographer at the City University of New York, provides a disturbing account of volunteers' experiences in The Professional Guinea Pig.

Phase I trials can be a risky business. In 2001, Ellen Roche, a previously healthy 24-year-old, died during a study of an asthma drug at Johns Hopkins University in Baltimore, Maryland. In 2006, at London's Northwick Park Hospital, six male volunteers were left in a critical condition after they were injected with an experimental treatment for rheumatoid arthritis and leukaemia (see Nature 440, 388-389; 2006).

With so much at stake for trial subjects, public protection and drug companies alike, the phase I system is worth examining. Abadie surmises that paid volunteers are here to stay, but that the commercial incentives that attract them put them in peril. More should be done to protect them, he says, including removing the veil of secrecy that currently makes it impossible for the public to know who these volunteers are, how many trials they have participated in, and what, if any, side effects they experience in the long term.

Abadie studied a group of 18 professional human guinea pigs who live from week to week on the money they are paid for intermittent drug trials. His interviewees were mostly white males living in communal houses, who supplemented their unpredictable income through temporary jobs. They came to his attention through Guinea Pig Zero, a small-

Drug blamed for
disastrous UK trial.
go.nature.com/imo2fd

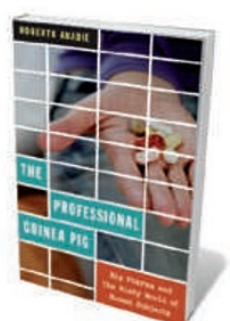

The Professional Guinea Pig: Big Pharma and the Risky World of Human Subjects ROBERTO ABADIE Duke University Press: 2010. 216 pp. $\$ 22.95$ by threatening to walk out halfway through tests of an anti-anxiety drug.

Abadie concedes that his group is not representative. The bulk of people who regularly enrol in phase I trials in Philadelphia - a hot spot for clinical studies because of the number of drug firms in the area - are African American or Hispanic, poor and relatively uneducated. They are also difficult to track down. Abadie points out that no demographic data are available on the whole phase I trial population. Companies disclose neither the number of trials they are conducting nor the number of subjects they enrol.

Money is the sole incentive for Abadie's professional guinea pigs. At the time of his research in 2003 and 2004, payments ranged from US $\$ 200-400$ a day for trials lasting three or four days, to $\$ 5,000$ for studies lasting up to four weeks. To fight attrition, the money is doled out in strategic increments, with the largest sum paid at the end. "You became addicted to the trials, to the easy money," one subject observes. But it is a coercive relationship, another admits. They sense that they are bodies for hire, with echoes of prostitution: Shon (a pseudonym) says that he experiences being stripped of his clothing and attached to a heart monitor as dehumanizing. "When they ask you to pee, you pee," says another.

The financial motive is in stark contrast to the altruistic or personal drivers of volunteers for phase II and III trials, who usually have the relevant disease for the drug being tested. Abadie interviewed for comparison a group involved in late tests of HIV drugs. These people took part because they wished to improve treatments generally, to benefit from them therapeutically if possible, and to gain a sense of empowerment in the fight against their disease.

The phase I subjects accept the short-term risks involved in trial participation - they perceive them as similar to, for instance, working in a restaurant kitchen. If they experience uncomfortable symptoms, they are reluctant to drop out because of the loss of pay. Between trials, they flush their bodies with diets of apples, cranberry juice and marigold flowers.

Most avoid thinking about the long-term risks. Abadie worries this is a consequence of the increasing sums being paid for phase I trials. Current ethical frameworks, he argues, inadequately address the effects of these incentives. Informed consent forms cover the trial at hand, but not the risks of serial trial participation. Abadie notes that the subjects lack the workforce stability and permanent community that support others in hazardous occupations, such as coal miners.

Conceding that payments for phase I trials will endure - a switch to an unpaid volunteer base would reduce numbers and almost halt drug development - Abadie recommends
"Subjects sense that they are bodies for hire, with echoes of prostitution." that greater occupational protections, such as the right to form or join labour organizations, be extended to subjects. However, he argues, the industry has tried to forestall such protections by calling subjects 'paid volunteers', placing them outside the umbrella of labour law in the United States.

Abadie also proposes the setting up of a centralized registry to identify all phase I participants, list the trials that each undertakes and document their short- and longterm side effects. To deter companies from performing unnecessary phase I trials, he suggests imposing a tax on those firms that test medicines that merely add to a class of therapies already on the market, favouring profit over scientific advancement.

Although the voice of the drug companies is missing from Abadie's ethnographic study, any improvement in the situation of phase I volunteers will need the industry's engagement. It is hard to imagine that the pharmaceutical industry will welcome his suggestions with open arms. But The Professional Guinea Pig raises important questions. It should not take another Ellen Roche or another Northwick Park for us to make these volunteers safer, and to dignify their important role.
Meredith Wadman is a biomedical reporter for Nature in Washington DC. 